\title{
De como o Brasil quase se tornou membro permanente do Conselho de Segurança da ONU em 1945
}

\author{
On how Brazil almost became a permanent member of the \\ United Nations Security Council in 1945
}

EUGÊNIO V. GARCIA*

Rev. Bras. Polít. Int. 54 (1): 159-177 [2011]

\section{Introdução}

A Organização das Nações Unidas (ONU) foi criada em 1945 sob o impacto dramático da Segunda Guerra Mundial. Seu propósito supremo podia ser expresso em uma única palavra: segurança. Entre outras fórmulas aventadas na época, o Presidente Franklin Delano Roosevelt acalentava a ideia de implantar um sistema chamado por ele de "tutela dos poderosos", a cargo dos Quatro Policiais: Estados Unidos, Grã-Bretanha, União Soviética e China, aos quais depois se somou a França. Na Conferência de Dumbarton Oaks, em 1944, foram aprovadas propostas para o estabelecimento da nova organização internacional, definindo a estrutura e o funcionamento de seus órgãos principais. O Conselho de Segurança ficaria encarregado de manter a paz e prevenir futuros atos de agressão, pela força se necessário. ${ }^{1}$ Mesmo ausente de Dumbarton Oaks, o Brasil foi o único país a ser cogitado naquela Conferência como possível detentor de uma sexta cadeira permanente no Conselho. Este artigo procura investigar como essa hipótese surgiu e se desenvolveu, assim como a atitude que assumiu o governo brasileiro e o desenlace da questão.

\section{Roosevelt lança seu balão de ensaio}

A ideia original dos Quatro Policiais nasceu de uma concepção regionalista de Roosevelt acerca do ordenamento mundial que deveria emergir após o conflito e impedir a eclosão de uma Terceira Guerra Mundial. As grandes potências deveriam

\footnotetext{
* Doutor em História das Relaçôes Internacionais pela Universidade de Brasília e diplomata. Este artigo é parte de pesquisa mais ampla realizada para a elaboração de Tese do LV Curso de Altos Estudos do Instituto Rio Branco, aprovada em outubro de 2010. As opiniôes aqui expressas são de exclusiva responsabilidade do autor (eugeniogarcia2005@yahoo.com).

1 Cf. HILDERBRAND, Robert. Dumbarton Oaks: the origins of the United Nations and the search for postwar security. Chapel Hill: The University of North Carolina Press, 1990.
} 
repartir seus deveres com a manutenção da segurança em cada região, evitando assim que os EUA ficassem obrigados a assumir compromissos militares por toda parte. Atuando de forma concertada, seria teoricamente possível aos Policiais fornecer razoável grau de "proteção" à Europa e à Ásia. No Oriente Médio, zona instável de encruzilhada de civilizaçôes entre a África e o continente euroasiático, Roosevelt flertou com a hipótese de sugerir um "Estado muçulmano" para o Conselho de Segurança. Tal sugestão, porém, nunca foi formalmente apresentada pelo governo norte-americano. ${ }^{2}$

$\mathrm{Na}$ América Latina, o país mais bem posicionado para eventualmente ser um dos Policiais - se essa escolha tivesse de ser feita - seria o Brasil. Embora os EUA fossem capazes de garantir sozinhos a segurança do Hemisfério Ocidental, poderia ser útil a Washington ter um firme aliado latino-americano no Conselho. Incluir o Brasil como membro permanente seria coerente com o grand design de Roosevelt para salvaguardar a paz mundial no pós-guerra, articulando as diferentes regiōes em torno de potências com peso específico em suas áreas geográficas, no marco institucional de uma organização que representaria foro universal de diplomacia parlamentar para todos os Estados "amantes da paz". Além disso, a colaboração brasileira aos Aliados havia sido em geral muito apreciada pelo governo norteamericano, em particular por Roosevelt e pelo secretário de Estado Cordell Hull, que consideravam o Brasil um modelo de "bom vizinho".

É possível que Roosevelt, além do reconhecimento pela contribuição brasileira durante a guerra, também tivesse genuína simpatia pelo Brasil, país que havia visitado duas vezes: a primeira em 1936, quando parou no Rio de Janeiro a caminho da Conferência Pan-americana de Buenos Aires, e a segunda em 1943, para a Cúpula de Natal. Em ambas as ocasiōes, seus encontros com Getúlio Vargas foram amistosos. Ficou-lhe a impressão de que o presidente brasileiro era um parceiro confiável, amigo dos EUA e comprometido com a defesa do continente americano. As credenciais pouco democráticas de Vargas não eram obstáculo a uma estreita cooperação entre os dois países. Enquanto prevalecessem os imperativos estratégicos da guerra e da alta política mundial, em tempos de polarização ideológica e embate global com o nazifascismo, de menor relevância era a natureza do regime político brasileiro. A longa noite autoritária do Estado Novo não obscurecia o fato de que o Brasil, com Vargas e Oswaldo Aranha, havia-se revelado um apoio vital aos EUA nos momentos de necessidade.

Não somente questôes de afinidade ou oportunismo teriam influenciado o ânimo de Roosevelt. Fatores conjunturais também tiveram seu papel. Importante nesse sentido era a percepção norte-americana do instável equilíbrio de forças na política sul-americana. A Argentina especificamente era vista como o "mau vizinho", que se mantinha apegado a uma neutralidade que mal disfarçava suas inclinações

2 Extracts from the personal diary of the Under Secretary of State (Stettinius), 31 ago. 1944, Foreign relations of the United States [doravante FRUS], 1944, vol. I. Washington: Government Printing Office, 1966, p. 758-759. 
pelo Eixo. Aos olhos de Washington, a Argentina em 1944 parecia longe de chegar ao ponto de ir à guerra contra o Eixo, o que outros países latino-americanos haviam feito desde 1942, como no caso do Brasil. A conjuntura regional parecia indicar ou ao menos não desautorizava - que uma política mais robusta de apoio ao Brasil, como contrapeso à influência argentina, teria guarida no quadro mais amplo dos objetivos norte-americanos para a região.

Assim, quando começou a Conferência de Dumbarton Oaks, havia um histórico recente que se coadunava com a visão favorável que Roosevelt tinha das relaçôes com o Brasil e com a abordagem regionalista que lhe era tão cara no projeto da ONU. Em 24 de agosto de 1944, durante reunião na Casa Branca sobre o andamento das negociações tripartites com a Grã-Bretanha e a URSS, foi discutida a possibilidade de ingresso da França e do Brasil como membros permanentes do Conselho de Segurança. Antecipando possíveis resistências, Roosevelt expressou seu entendimento de que a delegação norte-americana poderia levantar a questão de um assento permanente adicional "em termos gerais", mas não deveria insistir no assunto por enquanto. Seria melhor que se fizessem apenas "referências informais" ao Brasil na discussão. ${ }^{3}$

Na sessão do Comitê Diretor Conjunto de Dumbarton Oaks, que teve lugar na manhã de 28 de agosto, o subsecretário de Estado Edward Stettinius, seguindo as instruções de Roosevelt, levantou pela primeira vez a questão do Brasil - que, diga-se de passagem, não havia sido previamente consultado a respeito. Indicou que mais à frente nas conversações sua delegação poderia desejar propor um sexto assento permanente no Conselho, a fim de poder acomodar algum dos países latino-americanos. O chefe da delegação soviética, Andrei Gromyko, inquiriu se Stettinius teria algum país específico em mente. Leo Pasvolsky, assessor norteamericano presente à reunião, respondeu que talvez pudesse ser o Brasil. Sobolev, delegado soviético, perguntou então quando o Brasil deveria ser incluído. Stettinius, vendo que a discussão estava indo muito mais longe do inicialmente pretendido, esclareceu que sua delegação não estava fazendo de fato uma proposta e tampouco estava sugerindo qualquer momento particular para tal aumento dos membros permanentes. O representante britânico, Alexander Cadogan, disse que se o número fosse aumentado para mais de cinco membros permanentes haveria "considerável confusão". Adiantou que informaria seu governo a respeito do caso brasileiro, mas duvidava que Londres contemplasse essa possibilidade. ${ }^{4}$

$\mathrm{Na}$ sequência da reunião, Gromyko indagou se a ideia norte-americana era inserir uma referência ao Brasil nas propostas a serem aprovadas em Dumbarton Oaks. Stettinius assinalou que poderia haver uma cláusula recomendando que um lugar fosse reservado à França e outro para os países latino-americanos. Gromyko

\footnotetext{
3 FRUS, 1944, vol. I, p. 730-732.

4 DILKS, David (ed.). The diaries of Sir Alexander Cadogan, 1938-1945. Nova York: Putnam's Sons, 1972, p. 653-654.
} 
aproveitou a ocasião para sublinhar que a delegação soviética era favorável a limitar os membros permanentes às quatro potências (China incluída) e à França. Stettinius escreveria depois em seu diário que era "óbvio" que os soviéticos preferiam somente cinco assentos permanentes. ${ }^{5}$

No mesmo dia, à tarde, Stettinius se encontrou com Roosevelt para repassar os vários tópicos discutidos na Conferência, entre eles o caso do Brasil. Relatou que as reaçôes tanto de britânicos quanto de soviéticos haviam sido "negativas". Opinou que se o presidente quisesse agora pressionar mais duramente o assunto seria "mais difícil". Roosevelt ponderou a questão e finalmente disse que ele pessoalmente estaria disposto a aceitar que não se nomeasse o Brasil na minuta inicial da Carta. Desejava, no entanto, que houvesse uma menção geral no projeto que deixasse a porta aberta para que o tema fosse futuramente tratado por ele com Churchill e Stalin, antes que a organização fosse efetivamente lançada. ${ }^{6}$

Em face das dificuldades encontradas, a delegação norte-americana se reuniu, em 31 de agosto, para avaliar de novo a situação. Diversas vozes se levantaram contra a proposta do sexto membro permanente e advogaram retirá-la tout court. Pasvolsky sustentou que outro assento desse tipo obrigaria a um aumento do número de não permanentes, se fosse mantido o princípio de maioria de assentos eletivos. O Conselho passaria a ter então 13 membros, número "agourento" que Roosevelt não aceitaria. Outros delegados argumentaram que a presença do Brasil reabriria o debate regional e poderia levar a pressōes para a incorporação de potências menores de outras regiôes. Foi também comentado que o Brasil não era uma "grande potência" e seu futuro político e econômico ainda era incerto. A "duvidosa capacidade militar do Brasil" poderia minar a justificativa principal para a concessão de privilégios aos membros permanentes, isto é, as potências vitoriosas na guerra que teriam depois maiores responsabilidades na paz. ${ }^{7}$ Esses e outros argumentos foram consolidados em um memorando sobre o lugar do Brasil no Conselho, escrito por Pasvolsky e outro assessor sênior, James Dunn. Os britânicos e soviéticos haviam rejeitado "enfaticamente" a proposta. À luz dessa oposição, alegava o texto, era preciso reconsiderar a atitude que havia sido tomada. A delegação norte-americana, após exaustivo estudo do assunto, recomendava "unanimemente" que os EUA não apoiassem o Brasil. ${ }^{8}$

Ainda no dia 31, Stettinius entregou o memorando Pasvolsky-Dunn a Roosevelt, que leu cuidadosamente o documento e de início não ficou impressionado. A maior parte das críticas da delegação norte-americana bem poderia ser aplicada à

5 Stettinius a Roosevelt, memorando, Washington, 28 ago. 1944, FRUS, 1944, vol. I, p. 737; CAMPBELL, Thomas \& HERRING, George. The diaries of Edward R. Stettinius Jr. Nova York: New Viewpoints, 1975, p. 111-113.

6 Matters to discuss with the President, Washington, 28 ago. 1944, FDR Papers, President's Secretary's File, Box 131, Dumbarton Oaks Conference.

7 HILDERBRAND. Dumbarton Oaks. op. cit. p. 123-128.

8 "Brazil's place on the Council", Stettinius a Roosevelt, memorando particular e pessoal, secreto, Washington, 31 ago. 1944, FDR Papers, President's Secretary's File, Box 131. 
China de Chungking ou à França gaullista, que não eram genuinamente grandes potências em 1944, segundo os próprios critérios que estavam sendo aventados. Os argumentos contra a expansão numérica do Conselho também teriam sido válidos quando do aumento de três para quatro ou cinco membros permanentes. Quanto à questão regional, Roosevelt não pensava em outro país que não fosse o Brasil para assumir o posto como representante da América Latina. Somente após árduo debate entre os dois, Roosevelt aceitou a recomendação de que não se insistisse na proposta em favor do Brasil, pelo menos àquela altura. Não se dando por vencido, Roosevelt afirmou que isso era "muito importante", pois algum dia ele poderia desejar propor um assento permanente para um país muçulmano. A questão do Brasil, emendou, era "uma carta na sua manga".

Com aval superior, Stettinius pôde então voltar a seus colegas em Dumbarton Oaks. Em 3 de setembro, nova reunião do Comitê Diretor Conjunto acolheu a proposição de que o Conselho de Segurança teria 11 membros no total e que a França receberia uma cadeira permanente "oportunamente". ${ }^{10}$ Em seguida, Stettinius lembrou a Cadogan e Gromyko que ele havia trazido anteriormente para exame a possibilidade de incluir o Brasil como sexto membro permanente. Em deferência às posições que as delegaçôes britânica e soviética assumiram, continuou, os EUA estavam retirando seu pedido para "melhor consideração" da questão. Em tom jocoso, Stettinius disse esperar com isso que a atitude norte-americana de "rápida e não solicitada" retirada da proposta, em assunto de importância para seu país, poderia servir de exemplo ou precedente no encaminhamento de outros itens da agenda da Conferência. Concluindo sua intervenção, sugeriu que talvez pudesse ser inserida no texto de Dumbarton Oaks uma cláusula geral que autorizasse um "possível aumento futuro do número de assentos permanentes". Ato contínuo, Cadogan respondeu que ele lamentava ser o primeiro a quebrar o precedente recém-estabelecido, pois esperava que tal cláusula não fosse necessária. Gromyko, secundando a posição britânica, acrescentou que também para ele a proposta não seria adequada naquele momento. Disposto a colocar uma pá de cal no assunto, Cadogan ainda ressaltou que, se no futuro fosse considerado "desejável" ter um sexto assento permanente, sempre poderia ser utilizado o processo de emendas à Carta. ${ }^{11}$ Depois disso, não mais se falou do Brasil durante a Conferência.

\section{Resistências internas e externas}

Até meados de 1944, todas as discussōes interaliadas sobre o Conselho de Segurança haviam ocorrido confidencialmente. A não ser pelos relatos que vazavam à imprensa e pelos comentários de jornalistas que conseguiam atravessar o véu de

9 FRUS, 1944, vol. I, p. 759; HILDERBRAND. op. cit. p. 127.

10 Stettinius a Roosevelt, memorando, Washington, 31 ago. 1944, FDR Papers, President's Secretary's File, Box 131 .

11 Stettinius a Hull, memorando, Washington, 3 set. 1944, FRUS, 1944, vol. I, p. 764-765. 
silêncio de Dumbarton Oaks, não se sabia ao certo qual o verdadeiro formato que a futura organização internacional assumiria. Carlos Martins, Embaixador em Washington, chegou a fazer gestóes junto ao Departamento de Estado para se queixar da "completa ignorância" na qual o governo brasileiro havia sido deixado em relação ao progresso da Conferência. ${ }^{12}$

A questão do assento permanente só se colocou de modo concreto para o governo brasileiro depois de recebido o memorando norte-americano de 9 de outubro, com o texto das propostas aprovadas em Dumbarton Oaks, simultaneamente enviado a inúmeras outras chancelarias. $\mathrm{O}$ mundo finalmente tomava conhecimento dos arranjos a que haviam chegado as quatro potências. Ministro interino das Relações Exteriores, Pedro Leão Velloso levou o assunto imediatamente ao conhecimento de Vargas no Catete. Depois que ambos examinaram o memorando, ficou definido o método de trabalho a seguir pelo Itamaraty. $\mathrm{O}$ presidente instruiu Leão Velloso a convocar uma comissão de notáveis para estudar o projeto, discuti-lo e orientar a formulação da resposta que o governo brasileiro encaminharia ao Departamento de Estado. O grupo incluía nomes conhecidos como Raul Fernandes, o ex-chanceler José Carlos de Macedo Soares, os juristas Levi Carneiro e Eduardo Espínola, e diversos embaixadores. ${ }^{13}$

Dentro do governo brasileiro, existia certo ceticismo com o projeto da organização mundial, dada a maneira como havia sido estruturado, com todas as suas deficiências e lacunas. Conforme relatou Raul Fernandes, na reunião de 20 de outubro da comissão de notáveis, a maioria dos presentes se manifestou contra o posto permanente no Conselho de Segurança alegando duas razóes principais: a) a posição acarretaria "imensas responsabilidades financeiras, políticas e militares, que não é do nosso interesse assumir"; e b) "a pretensão infalivelmente seria rejeitada". Apresentando-a, vaticinou Fernandes, "iríamos colher vexame certo". O Brasil colocaria os EUA em posição desagradável e "suscitaríamos contra nós, só com ser apresentada, as suscetibilidades das outras Repúblicas americanas". ${ }^{14}$ Assim, desde o início, ergueu-se relativo consenso de que o assunto era delicado e exigia discrição. Se o Brasil apresentasse um pleito notoriamente ostensivo, poderia ter de enfrentar depois uma situação de desprestígio em caso de recusa. Possivelmente por isso mesmo Vargas evitou abordar a questão em declarações públicas. Não obstante, indiretamente fez ver que ele próprio considerava de bom alvitre que o Brasil fosse reconhecido por sua lealdade à causa aliada.

Para que a linha de discrição fosse seguida, a estratégia esboçada passaria então por contatos bilaterais reservados com os EUA. Pensava-se que essa seria a melhor forma de conduzir tema tão sensível e - se realmente desse resultado - começar a

12 FRUS, 1944, vol. I, p. 924-925.

13 VELLOSO, Pedro Leão. O Brasil na Conferência de S. Francisco. Rio de Janeiro: Imprensa Nacional, 1945, p. 10-11.

14 Fernandes a Leão Velloso, memorando, RJ, 21 out. 1944, Arquivo Histórico do Itamaraty [doravante AHI] Lata 651, Maço 9803-A. 
receber as esperadas "compensações" por tudo o que o Brasil havia feito em prol dos Aliados. Vargas deu sinal verde a Leão Velloso para que o Itamaraty fizesse gestóes junto ao governo norte-americano. Em conversas com o encarregado de negócios dos EUA no Rio de Janeiro, Walter Donnelly, Leão Velloso ressaltou a importância que o governo brasileiro ligava ao assunto. Comentou que o embaixador Carlos Martins havia sido informado em Washington de que, durante a recente Conferência de Québec, Roosevelt teria falado sobre isso com Churchill em resposta à recomendação britânica de fazer da França um dos membros do Conselho. Roosevelt teria dito: "Se nós concordarmos com a França, então eu devo cuidar dos meus bons amigos brasileiros, porque eles vão esperar serem incluídos no Conselho Permanente [sic]". ${ }^{15}$

Ao que tudo indica, em meados de outubro Roosevelt ainda nutria esperanças com relação ao Brasil no Conselho, mesmo havendo aprovado - com relutância o memorando Pasvolsky-Dunn, que recomendava o contrário. O fato de que Stettinius retirara o tema da pauta em Dumbarton Oaks não significava que o presidente simplesmente havia abdicado por completo de ver sua ideia realizada. Ele havia pessoalmente patrocinado a China e obtido sucesso, a despeito das críticas à reconhecida "fraqueza" chinesa. Na perspectiva regionalista que Roosevelt acalentava, o status de grande potência não era exigência tão fundamental se o país escolhido pudesse desincumbir-se a contento ao menos em sua própria região, em colaboração com os EUA. Mas, se a proposta tinha seus detratores dentro do próprio governo norte-americano, as objeçōes levantadas por soviéticos e britânicos representavam óbice de peso, capaz de frear a iniciativa se não houvesse forte empenho de Washington. Faz-se mister, pois, examinar melhor os dois casos.

O Brasil e a União Soviética não mantinham relações diplomáticas em 1944. Na verdade, os contatos oficiais entre os dois países eram inexistentes desde o triunfo da Revolução Russa. O governo brasileiro não havia reconhecido o regime bolchevique em 1917 e fechara sua Legação na capital russa. O governo de Moscou, que tampouco tinha representação diplomática no Rio de Janeiro, estava cabalmente informado do sentimento antissoviético que prevalecia entre as elites políticas e militares brasileiras, sobretudo após a chamada Intentona Comunista de 1935. A "estranha aliança" da URSS com as potências ocidentais na Segunda Guerra Mundial não chegou a alterar completamente o quadro mais profundo de antipatia pelas ideias socialistas entre membros da cúpula do Estado Novo, que não dissociavam o governo soviético do movimento comunista internacional. Em 1942, tentativas de aproximação entre o Brasil e a URSS foram rechaçadas por Vargas, que não queria dar a impressão de estar "no mesmo barco" com os soviéticos. As relações bilaterais trilhavam caminho incerto e repleto de desconfianças dos dois lados. Diante disso, Stalin não tinha motivação concreta e substancial para acolher a proposta norte-americana. Mas poderia bloqueá-la?

15 FRUS, 1944, vol. I, p. 932-933. 
Com sua percepção crua da Realpolitik, Stalin valorizava a força e via com desprezo os países pequenos, sem poder militar expressivo. Na sua visão, às grandes potências - e somente elas - deveria caber a responsabilidade de gerir os assuntos pertinentes à ordem global. Os Três Grandes seriam os únicos a preencher esse critério de poder. A URSS havia aceitado a contragosto o ingresso da China e da França entre os membros permanentes, por insistência dos EUA e da Grã-Bretanha respectivamente. Seria mais um teste de vontade fazer com que os soviéticos apoiassem a entrada de qualquer outro país adicional que não fosse considerado uma potência forte o bastante para figurar entre os grandes. ${ }^{16}$ Havia o receio de que quanto mais atores no Conselho, mais poderia diluir-se o poder da URSS no órgão. Além disso, politicamente alinhado aos EUA, o Brasil poderia significar um voto extra para Washington, com a possibilidade não apenas teórica de que França e China pudessem também cerrar fileiras com os dois países anglo-saxōes (EUA e Grã-Bretanha). Como a URSS já se sentia em menor número no Conselho, esse cenário não atraía Stalin, muito pelo contrário.

A Grã-Bretanha, por sua vez, não tinha objeção específica ao Brasil, país com o qual mantinha relações corretas, amigáveis, ainda que não fossem "excelentes". No fundo, o Brasil não era politicamente fundamental para a Grã-Bretanha, cujas prioridades de política externa passavam primeiro pelas relações transatlânticas (EUA), pela Europa e pelo Império Britânico, espalhado em diversos continentes. Nas questões de preparação para a paz, o governo de Londres costumava coordenar sua posição com os Domínios, que participavam ativamente da guerra, inclusive com tropas de combate. Depois de haver-se batido pela inclusão da França no Conselho, Churchill não podia encampar mais um candidato a assento permanente sem se indispor com seus parceiros da Comunidade Britânica. Já havendo cedido aos desejos norte-americanos no caso da incorporação da China, seria mesmo difícil que Churchill pudesse explicar aos Domínios que apoiaria ainda outro país proposto pelos EUA, deixando de fora o Canadá ou a Austrália, que também vinham fazendo sacrifícios em prol da causa aliada e, muito especialmente, em defesa de Sua Majestade Britânica e da sobrevivência da Grã-Bretanha nas horas mais soturnas da guerra. Para o Foreign Office, criar um sexto assento permanente seria o mesmo que "mexer num vespeiro". ${ }^{17}$

Outro ponto importante era a própria visão britânica do Conselho de Segurança a ser criado, influenciada pelo regionalismo de Churchill. A GrãBretanha não queria arcar sozinha com os custos de manter a ordem no pósguerra. Com a economia em frangalhos, o país tinha sérios problemas internos e um Império imenso para cuidar, com crescente dificuldade para conter revoltas e pressōes por maior autonomia, como na Índia. Seu poder claramente havia

16 SCHILD, Georg. Bretton Woods and Dumbarton Oaks: American economic and political postwar planning in the Summer of 1944. Nova York: St. Martin's Press, 1995, p. 144.

17 "Position of Brazil in World Organisation Council", Embaixada britânica em Washington ao Foreign Office, ofício, 7 out. 1944, National Archives, Kew, FO 371/40720. 
diminuído, embora sua real condição estivesse oculta pela ilusória sensação de poder gerada pela vitória. Para Churchill, os EUA policiariam o hemisfério ocidental e idealmente dariam sua contribuição para manter a segurança na Europa, servindo como garante contra qualquer pretensão futura alemã e anteparo ao expansionismo soviético no continente europeu. No Extremo Oriente, EUA e URSS poderiam juntos controlar o Japão (eventualmente com assistência chinesa). Ainda que muito debilitada, a França repartiria o fardo com a Grã-Bretanha na Europa e em áreas extraeuropeias onde houvesse uma presença colonial francesa paralela à britânica (África, Oriente Médio ou mesmo no Sudeste Asiático). Nesse esquema, todas as principais regiōes do globo estariam cobertas. Para fins exclusivos de segurança, finalidade primeira e última do Conselho, não haveria então por que incluir um sexto membro permanente, fosse ele qual fosse.

\section{Os Estados Unidos recuam}

Entrementes, mudanças na chefia do Departamento de Estado teriam impacto no desenrolar das tratativas. Hull, com sua saúde severamente debilitada há um bom tempo, teve de ser hospitalizado e renunciou ao cargo em 27 de novembro de 1944. Para seu lugar foi nomeado Stettinius, com a promessa de "revitalizar" o Departamento. ${ }^{18}$ Stettinius não havia compartilhado das experiências anteriores de Roosevelt e Hull na política hemisférica. Não se sentia previamente comprometido e muito menos entusiasmado com o Brasil. O novo secretário de Estado podia agora dar livre curso às suas próprias visōes sobre o caso brasileiro, que no contexto da guerra e da pesada agenda interna de Roosevelt - convém sempre ter presente não estava no topo da lista de prioridades do governo norte-americano. Desde outubro, Roosevelt dividia seu tempo entre governar os EUA, acompanhar a guerra e conduzir sua campanha eleitoral para um quarto mandato. ${ }^{19}$

Em 18 de dezembro, procurando dar um ponto final na questão, Stettinius telegrafou à embaixada no Rio de Janeiro para transmitir a posição de seu governo em relação às aspirações brasileiras. Os EUA estavam preparados a dar "forte apoio" a um assento não permanente para o Brasil. Quanto à alocação ao Brasil de um assento permanente, Stettinius foi incisivo ao afirmar que os EUA não iriam insistir nisso. Entre as razões para tanto, anotou, estava o fato de que as perspectivas de sucesso, sem o apoio ativo da URSS, seriam em termos práticos "desprezíveis". O esforço seria não apenas "infrutífero", mas enfraqueceria também a posição norte-americana em outros assuntos importantes. Havia uma "oposição resoluta" ao aumento da composição do Conselho acima da proposta de 11 membros (cinco permanentes e seis não permanentes). Elevar o número de cadeiras permanentes,

18 CAMPBELL, Thomas. Masquerade peace: America's UN policy, 1944-1945. Tallahassee: Florida State University Press, 1973, p. 68.

19 HOOPES, Townsend \& BRINKLEY, Douglas. FDR and the creation of the U.N. New Haven: Yale University Press, 1997, p. 164. 
advertiu, implicaria reduzir para cinco o número de não permanentes, "com o sacrifício de outros interesses vitais". Stettinius lançou mão do argumento do poder militar, dentro de uma visão globalista do papel da organização. Segundo ele, um fator preponderante na seleção dos cinco membros permanentes, entre outros, era a "contribuição estimada" que poderiam dar, quando a necessidade surgisse, à imposição da paz "em qualquer parte do mundo, incluindo o Extremo Oriente". Stettinius concluiu indicando que o governo norte-americano acreditava ser de interesse do Brasil não continuar pressionando por uma cadeira permanente a essa altura. Pediu, finalmente, que a embaixada confirmasse se o Brasil "ficaria satisfeito" com as garantias de apoio do governo dos EUA a um assento não permanente. ${ }^{20}$

Para que não ficasse dúvida quanto ao conteúdo exato da mensagem que se queria fazer chegar ao governo brasileiro, o texto do telegrama de Stettinius foi mostrado confidencialmente a Carlos Martins, que preveniu Leão Velloso. O Itamaraty estava, portanto, de antemão avisado de que não poderia contar com o endosso norte-americano naquelas circunstâncias. Para o embaixador brasileiro, as razões apresentadas contra o Brasil eram "fúteis", mas o momento era o menos aconselhável para tentar reverter o quadro. O Departamento de Estado estava sem ninguém que tratasse dos negócios das Américas "com influência bastante para interceder" e as relações políticas entre os Três Grandes atravessavam um período delicado, que não permitia aos EUA defender a reivindicação brasileira. ${ }^{21}$

Compelido a obter uma resposta, o encarregado de negócios Donnelly informou alguns dias depois que Leão Velloso lhe dissera que o governo brasileiro "obviamente" preferia e considerava que tinha direito a um assento permanente. No entanto, se isso não pudesse ser arranjado, o Brasil deveria então receber um dos primeiros assentos não permanentes. Essa indicação de aparente desistência em sustentar o pleito levou Donnelly a avaliar (usando as mesmas palavras de Stettinius) que o Brasil "ficaria satisfeito" em ser membro temporário do Conselho - de resto, exatamente aquilo que o Departamento de Estado desejava ouvir. ${ }^{22}$

\section{A candidatura indireta}

Alguns temas laboriosamente esmiuçados em Dumbarton Oaks, como o sistema de votação no Conselho de Segurança, foram postergados para a consideração dos Três Grandes na Cúpula de fevereiro de 1945, na Crimeia. No entanto, nas muitas fontes disponíveis sobre Yalta, não aparecem registros de que haja sido discutida naquela reunião a possibilidade de ser alocado um assento permanente para o Brasil. Admite-se, por uma questão de método, que Roosevelt poderia ter levantado o assunto em conversa a sós com Churchill ou Stalin, à

20 FRUS, 1944, vol. I, p. 952.

21 Martins a Leão Velloso, tel., Washington, 19 dez. 1944, AHI 51/5/6.

22 FRUS, 1944, vol. I, p. 952-953. 
margem das sessões formais da Conferência, sem a presença de ministros, secretários ou assessores, e sem que ficassem notas ou transcrições que servissem de evidência. Essa hipótese, todavia, é improvável.

Pode-se especular acerca das razões que levaram Roosevelt a arquivar sua proposta, entre elas a massa avassaladora de pendências mais urgentes a resolver, sua debilidade física crescente ou, também possível, que ele se havia deixado convencer de que, sem os apoios necessários da URSS ou da Grã-Bretanha, tratava-se de uma partida perdida. Mas o fato é que, depois das resistências enfrentadas em Dumbarton Oaks - inclusive dentro da delegação norte-americana - e da decisão de fechar em cinco o número de membros permanentes no Conselho, a questão do Brasil perdera momentum.

Antes que terminasse o ano de 1944, o assunto era dado por liquidado nos círculos governamentais em Washington. Recém-nomeado secretário de Estado, Stettinius havia definido que Vargas deveria contentar-se com o "incentivo" dos EUA para que o Brasil concorresse às eleições para membros não permanentes. Assim, logo após Yalta, nos pontos de conversação que Roosevelt usaria na Conferência de São Francisco, preparados pelo Departamento de Estado, não se faz referência à matéria, a não ser para ressaltar, incidentalmente, que alguns "problemas importantes" surgiam para os EUA em função das "ambições brasileiras de ser uma potência mundial com representação constante em qualquer organização mundial". ${ }^{23}$

No Brasil, como já assinalado, não havia consenso sobre o que convinha fazer. O embaixador Hildebrando Accioly, juntamente com Raul Fernandes e José Carlos de Macedo Soares, pertencia ao grupo que tinha restrições quanto à participação do Brasil no Conselho de Segurança. Terá pesado na consideração do problema a memória da crise de 1926 na Liga das Nações e a retirada do Brasil, em meio a críticas e condenações, após o fracassado intento de obter uma cadeira permanente no Conselho Executivo daquela organização. ${ }^{24}$ Para os céticos, evitar a repetição de uma situação constrangedora como a de 1926 parecia ser motivo forte a desestimular nova investida na organização mundial que se ia criar em 1945. Leão Velloso tentava manter-se neutro, mas reservadamente simpatizava com o grupo de Accioly.

A outra corrente, encabeçada por Getúlio Vargas, contava com Carlos Martins, Cyro de Freitas-Valle e outros diplomatas e juristas que queriam ver o Brasil reconhecido por sua contribuição à guerra e pela grandeza de seu território, população e posição na América do Sul. Vez por outra circulavam manifestações espontâneas de apoio de diversos publicistas animados dos "mais elevados sentimentos patrióticos”. A experiência da Liga das Nações também era lembrada, mas por outro prisma, como o fez Levi Carneiro: "Creio que um dever

23 Political Memoranda, State Department, 1945, FDR Papers, President's Secretary's File, Box 6.

24 GARCIA, Eugênio V. Entre América e Europa: a política externa brasileira na década de 1920. Brasília: Editora UnB/FUNAG, 2006, p. 423. 
de coerência, de continuidade, impõe-nos a apresentação dessa candidatura. Porque não minguaram as razões em que nos apoiávamos, há quase 20 anos, pleiteando um lugar no Conselho da Sociedade das Nações. Ao contrário, avultaram, e outras sobrevieram". Carneiro mencionou algumas das credenciais que o Brasil possuía para aspirar ao cargo: o esforço militar brasileiro na guerra em curso; a relevância da posição estratégica do país; o fato de ser a décima nação do mundo em população; ser a maior nação latina, depois da França, sem ter assegurada sua participação no Conselho; grau de desenvolvimento econômico e acervo de matérias-primas ainda inexploradas; "sem falar na tradição liberal, democrática, ordeira, com que sempre se enobreceu o Brasil". ${ }^{25}$

Bem ao seu estilo, Vargas instruiu Leão Velloso no sentido de procurar satisfazer as "justas aspirações do país", sem deixar de levar em conta as ponderações e conselhos das autoridades que se pronunciaram em contrário. A fórmula de pleitear um lugar permanente no Conselho para a América Latina, sem menção ao Brasil, surgiu como solução intermediária entre a resistência de algumas altas personalidades do meio diplomático e um sentimento difuso da opinião pública nacional favorável ao assento permanente. Pode-se dizer que se tratava de uma candidatura indireta. Confiava-se em que, se aprovado um assento permanente a mais no Conselho, o apoio norte-americano (especialmente de Roosevelt) garantiria a elevação do Brasil a esse posto. Seria uma consequência natural da pretendida entente Brasil-EUA. Assim, no memorando encaminhado à embaixada norte-americana, em 4 de novembro de 1944, com os comentários do governo brasileiro sobre as propostas de Dumbarton Oaks, um dos pontos destacados foi a necessidade de que o Conselho de Segurança refletisse as diversas correntes de opinião e de interesses existentes no mundo. O Brasil declarou então que julgava "indispensável" atribuir à América Latina um assento permanente.

A mesma posição seria levada pelo governo brasileiro à Conferência Interamericana sobre os Problemas da Guerra e da Paz, inaugurada em fevereiro de 1945 no Castelo de Chapultepec, na Cidade do México. Após prolongados debates, a Conferência adotou a Resolução XXX: sete recomendações foram apresentadas sobre a organização mundial, entre elas "a conveniência de dar representação adequada à América Latina no Conselho de Segurança”. ${ }^{26}$

Nas instruçóes oficiais que redigiu para a delegação do Brasil à Conferência de São Francisco, Hildebrando Accioly considerava "geral e legítimo" o desejo dos países latino-americanos de se verem representados adequadamente. Em Chapultepec, alguns países, incluindo o Brasil, favoreceram fórmulas mais democráticas para a composição do Conselho, "suprimindo-se o privilégio dos lugares permanentes, contrário ao princípio da igualdade jurídica das nações". A delegação do Brasil, em todo caso, "não insistiu sobre estes pontos, convencida

25 Levi Carneiro a Leão Velloso, memorando, RJ, 23 out. 1944, AHI Lata 651.

26 Relatório do MRE, 1944. Rio de Janeiro: Imprensa Nacional, 1949, p. 27. 
de que: $1^{\circ}$ ) as grandes potências não abrirão mão do referido privilégio; $\left.2^{\circ}\right)$ dificilmente poderiam concordar em admitir mais algum lugar permanente no Conselho de Segurança". ${ }^{27}$

Era, portanto, com incredulidade que o Itamaraty via a perspectiva de alterar o plano original de Dumbarton Oaks. A posição que a delegação brasileira deveria adotar em São Francisco seria então a seguinte: "Na verdade, parece-nos inevitável a aceitação da ideia dos lugares permanentes, concedidos às cinco grandes potências. Se, todavia, for resolvido aumentar esse número para seis, o sexto lugar só poderá caber, logicamente, ao Brasil, devido à sua grandeza territorial, à sua população, às suas possibilidades econômicas e ao seu atual esforço de guerra, em prol da causa das Nações Unidas. Não julgamos, porém, que devamos pleitear a criação desse sexto lugar, porque: $1^{\circ}$ ) não estamos talvez em condições de arcar com as graves responsabilidades que acarreta semelhante posição; $2^{\circ}$ ) a escolha do Brasil levantaria, provavelmente, contra nós grandes invejas, da parte de várias nações latino-americanas; $3^{\circ}$ ) não podemos concordar em que o mesmo lugar seja ocupado por nenhuma outra nação". ${ }^{28}$

A julgar somente por essas instruções, o Brasil adotaria um perfil baixíssimo nas discussões sobre a composição do Conselho. Sequer deveria reivindicar a criação de um sexto lugar permanente para a América Latina. Não foi bem isso que ocorreu. A cautela seria sim uma das marcas características da atuação brasileira em São Francisco, em quase todos os itens da agenda. Mas a fórmula autorizada por Vargas foi a que prevaleceu. No âmbito da terceira Comissão da Conferência, ao Comitê 1 cabia analisar as emendas sobre a estrutura e o processo no Conselho de Segurança. O Brasil apresentou ali uma proposta de emenda à Carta que defendia a representação permanente da América Latina. Era, de novo, a candidatura indireta.

Enquanto isso, a morte de Roosevelt, imediatamente sucedido pelo vicepresidente Harry Truman, em 12 de abril de 1945, representou duro golpe às aspirações brasileiras. Roosevelt, com seu continuado apoio a Vargas, havia sido grande simpatizante da causa brasileira. $\mathrm{O}$ ex-secretário de Estado Hull, que havia sido um dos mentores da aliança de guerra entre os dois países, estava agora acamado no hospital e sem condiçóes de exercer influência. O embaixador Jefferson Caffery, que a tudo acompanhara do Rio de Janeiro, nos anos mais difíceis do conflito, havia sido recentemente substituído por Adolf Berle, que apenas começava sua missão no posto. Nessa lista poderia ser igualmente incluído Sumner Welles, fora do Departamento de Estado desde meados de 1943. Quando era subsecretário de Estado, Welles se havia empenhado em fazer do Brasil o principal aliado dos EUA na América do Sul, em perfeita sintonia de propósitos com Oswaldo Aranha, seu principal confidente em assuntos hemisféricos e outro que também saíra de cena em agosto de 1944. Truman e Stettinius, a nova dupla no comando, não tinham

27 Conferência de Organização Internacional das Nações Unidas, Instruções à Delegação do Brasil, RJ, 12 abr. 1945, Coordenação de Documentação Diplomática [doravante CDO], MRE, Brasília, Maço 42.942, p. 7. 28 Ibid. p. 15-16. 
histórico de envolvimento com assuntos brasileiros. A alavancagem que o Brasil em algum momento veio a possuir, pelo menos nesse terreno, havia-se evaporado.

\section{Última chance: o Brasil em São Francisco}

Durante a Conferência de São Francisco, Leão Velloso abordou a questão em conversa com Stettinius, em 3 de maio de 1945. O secretário de Estado lhe respondeu que o aumento dos lugares permanentes no Conselho não havia sido tratado ainda pelos chefes das delegações das quatro potências patrocinadoras. Segundo o relato que Leão Velloso transmitiu a Vargas, Stettinius prometeu provocar a discussão do assunto na próxima reunião dos quatro países e manter a delegação brasileira informada. "Prometeu, também, que na hipótese de ser resolvida a criação de um sexto lugar permanente no Conselho de Segurança, ele sugeriria que fosse oferecido ao Brasil". ${ }^{29}$ Essa promessa Stettinius nunca cumpriu. Para cumpri-la era preciso que em algum momento fosse suscitada novamente a hipótese do sexto assento, mas ele próprio não tinha a mais leve intenção de reabrir uma questão que considerava fechada desde Dumbarton Oaks.

Em 8 de maio, os delegados interromperam momentaneamente as negociações para celebrar o Dia da Vitória das forças aliadas na Europa. Do Rio de Janeiro, em curto telegrama a Leão Velloso, Vargas parecia triunfante: "Nosso povo, desde ontem, festeja com entusiasmo a vitória comum. Pelas nossas bases milhares de aviōes começarão, em breve, a passar em trânsito da Europa para a Ásia. Parece justo o reconhecimento nessa Conferência do valor da nossa colaboração e sacrifício, assegurando-nos um lugar permanente no Conselho". ${ }^{30}$

Ao acusar recebimento da mensagem, Leão Velloso logo indicou que daria conhecimento a Stettinius do telegrama presidencial, a seu ver uma maneira de mostrar ao secretário de Estado que a aspiração brasileira partia, em primeiro lugar, do próprio chefe da nação. Aproveitou para prestar contas a Vargas de suas gestôes em prol do assento permanente desde sua chegada a São Francisco: "Conheço a natural expectativa do povo brasileiro e, por conseguinte, essa tem sido a minha principal preocupação". Mencionou a promessa de Stettinius de apoiar o Brasil na hipótese de ser aumentado o número de cadeiras no Conselho. Em sondagem junto ao secretário do exterior britânico, Anthony Eden, este lhe dissera "com toda a franqueza" que era pessoalmente contrário a incluir novos membros no referido órgão. ${ }^{31}$

Para corresponder aos desejos expressos por Vargas, Leão Velloso escreveu uma carta a Stettinius, em 14 de maio. Lembrou-o da cópia que enviara a Stettinius

29 Leão Velloso a Vargas, tel. secreto, São Francisco, 3 maio 1945, CDO, Pasta 602 (04) ONU Diversos 19451957; CPDOC, GV c 45.04.30.

30 Vargas a Leão Velloso, tel. reservado nº 1, RJ, 8 maio 1945, CPDOC, GV c 45.04.30.

31 Leão Velloso a Vargas, tel. secreto, São Francisco, 10 maio 1945, CDO, Pasta 602 (04) ONU Diversos 1945-1957; CPDOC, GV c 45.04.30. 
do telegrama do Presidente, com o alto parecer de Vargas sobre a questão. "Esse telegrama", afirmou, "era a confirmação do que eu lhe dissera pessoalmente sobre a expectativa do povo brasileiro a esse respeito". Salientou que a contribuição militar do Brasil para a guerra, cujo valor havia sido sempre reconhecido pelos EUA, justificava "plenamente" essa aspiração. E insistiu na ideia de que negar esse lugar causaria frustração no Brasil, com indesejáveis repercussões futuras: "Não tenhamos dúvida sobre a profunda decepção que seria para o povo brasileiro verificar que não lhe são reconhecidos os sacrifícios que, com o povo dos EUA e do Canadá, ele foi o único a fazer na América em favor da vitória das armas aliadas". 32

A carta de resposta de Stettinius tardaria a chegar, mas, antes disso, é possível que Leão Velloso haja sido avisado verbalmente por algum delegado norteamericano, no mesmo dia, da impossibilidade de atender à reivindicação do Brasil. Afinal, na sétima reunião do Comitê 1 da terceira Comissão, que também teve lugar em 14 de maio, à noite, a delegação brasileira retirou sua proposta relativa à representação permanente da América Latina, visto que isso implicaria aumento na composição total do Conselho. Como resultado, o Comitê tomou a decisão de "não favorecer a criação de um sexto assento permanente representando a América Latina”. ${ }^{33}$ Em consonância com a diretriz básica adotada, de não expor o Brasil a situações embaraçosas que denotassem qualquer sombra de fiasco, a retirada da proposta pelos delegados brasileiros evitou que seu texto fosse levado a votação e, com grande probabilidade, sofresse uma derrota. Esse foi o dia em que, definitivamente, o Brasil "jogou a toalha” e considerou irrealizável a obtenção do assento permanente.

Poucos dias depois, em 19 de maio, Leão Velloso informou Vargas da carta que havia dirigido a Stettinius "para obrigá-lo a me dar uma resposta concreta por escrito". A pretensão brasileira se baseava tanto na cooperação que havia sido prestada na guerra quanto na importância que se atribuía à posição do país no futuro plano de segurança mundial. Para agregar dramaticidade ao pedido de apoio, deixou entrever a possibilidade de eventuais "consequências, sobre as nossas relações com os Estados Unidos, da nossa decepção caso não fôssemos atendidos". Mas Leão Velloso tinha consciência das dificuldades e, tudo indica, já sabia que a resposta norte-americana seria negativa. ${ }^{34}$ Vargas aprovou a démarche e o tom geral da atuação de seu chanceler interino: "Estou de acordo com a atitude discreta e cautelosa que tem Vossa Excelência seguido nessa Conferência”. ${ }^{35}$ O Presidente brasileiro não voltaria mais a tocar no assunto do assento permanente.

32 Leão Velloso a Stettinius, carta, São Francisco, 14 maio 1945, CDO, Maço 42.982.

33 Summary Report of Seventh Meeting of Committee III/1, Veteran's Building, Room 223, 14 May 1945. Documents of the United Nations Conference on International Organization, San Francisco. Nova York: United Nations Information Organization, 1945, vol. XI, p. 290.

34 Leão Velloso a Vargas, tel. secreto, São Francisco, 19 maio 1945, CDO, Pasta 602 (04) ONU Diversos 1945-1957; CPDOC, GV c 45.04.30.

35 Vargas a Leão Velloso, tel. confidencial, RJ, 21 maio 1945, CPDOC, GV c 45.04.30. 
Em 23 de maio, Leão Velloso e Carlos Martins conversaram com Nelson Rockefeller, secretário de Estado assistente para as repúblicas americanas. O delegado norte-americano havia acabado de receber de Washington um telefonema de Stettinius, que lá se encontrava para tratar do andamento da Conferência com o presidente Truman. Rockefeller adiantou que não haveria aumento do número de cadeiras permanentes. Em compensação, o Brasil podia contar com o apoio norte-americano a um assento não permanente com mandato de dois anos. Leão Velloso se apressou em comunicar a decisão a Vargas: "Não nos será possível obter o lugar permanente pela razão que já expus a Vossa Excelência, isto é, a relutância das quatro potências em aumentar o número dos assentos do Conselho de Segurança. Teremos no mesmo Conselho, com o apoio dos Estados Unidos, um lugar não permanente por dois anos, quando a Assembleia proceder à eleição dos lugares dessa categoria, ao passo que o México ou outro país latino-americano será eleito apenas por um ano". ${ }^{36}$ A atitude da delegação brasileira se explica em grande medida pela percepção de que se tratava, desde o início, de uma "questão encerrada", conforme avaliação do próprio Leão Velloso, que se deu por satisfeito com o "valioso apoio" obtido dos EUA para a posterior eleição do Brasil como um dos membros não permanentes, ocorrida em janeiro de $1946 .{ }^{37}$

A carta de resposta de Stettinius, agora mera formalidade, finalmente chegou em 13 de junho. O secretário de Estado assegurou Leão Velloso de que a aspiração do Brasil havia recebido "nossa mais simpática consideração" e havia sido "plenamente discutida e explorada" pelos EUA. O governo norte-americano tinha consciência da "cooperação cordial e completa" que existia entre os dois países, particularmente durante os recentes anos de conflito. Estava ciente também da "grande contribuição" que o Brasil havia dado na guerra contra o Eixo e da posição que o país iria assumir no futuro. Ao mesmo tempo, continuou, as nações que patrocinavam a Conferência "sentiam a necessidade de envidar todos os esforços possíveis para preservar a flexibilidade da organização mundial" e, com esse objetivo, concluíram que era melhor "não haver mais designação permanente de assentos no Conselho de Segurança". ${ }^{38}$

Desinteressado do assunto, o governo norte-americano parecia querer responsabilizar as outras potências que se opunham a um Conselho demasiadamente alargado. A Grã-Bretanha se encaixava nesse perfil, sustentando que um órgão com poucos membros seria "mais eficaz". Mas a oposição britânica não se pautava apenas por isso. É de se notar que esse ponto ótimo de "eficiência" foi atingido precisamente depois que Churchill conseguiu incluir a França entre os cinco membros permanentes. Como já dito, era politicamente difícil à Grã-Bretanha

36 Leão Velloso a Vargas, tel. secreto, São Francisco, 23 maio 1945, CDO, Maço 42.976; CPDOC, GV c 45.04.30.

37 Relatório da delegaçãa do Brasil à Conferência das Naçōes Unidas para a Organização Internacional. Rio de Janeiro: MRE, 1945, mimeo, p. 8.

38 Stettinius a Leão Velloso, carta, São Francisco, 13 jun. 1945, CDO, Maço 42.918. 
apoiar o Brasil se isso significasse a exclusão de seus Domínios. Explicação mais singela, porém válida também para a oposição soviética, consiste em reconhecer que o Brasil era indesejado simplesmente porque, uma vez no Conselho, representaria possivelmente mais um "voto certo" a favor dos EUA.

\section{A janela que se fechou em 1945}

O Brasil era visto em Washington como parceiro confrável e "aliado fiel". No entanto, a consideração dada por Roosevelt à possibilidade de fazer do Brasil o sexto membro permanente não foi uma iniciativa meticulosamente preparada nem chegou a ser amadurecida previamente nos círculos decisórios norte-americanos. Antes do final de 1944, a embaixada norte-americana no Rio de Janeiro já havia sido notificada pelo Departamento de Estado de que o apoio dos EUA seria limitado à eleição do Brasil a um lugar não permanente. Tomada essa decisão, o assunto não foi discutido por Roosevelt na Conferência de Yalta. O presidente norte-americano, que se havia empenhado pessoalmente em favor da China, vencendo as objeções de Churchill e Stalin, era quem melhor poderia levar adiante sua intenção de criar mais uma cadeira permanente. A morte de Roosevelt, pouco antes da Conferência de São Francisco, eliminou em definitivo essa possibilidade.

As principais alegações levantadas contra o sexto assento foram aplicadas seletivamente. A ênfase então atribuída ao poder militar tinha como parâmetro a mobilização maciça de forças na guerra em curso. Mas a tese de que era preciso ter status de grande potência como "pré-requisito" não impediu que o governo chinês de Chungking, que controlava apenas uma fração de seu próprio território, fosse convidado a ser um dos Policiais em virtude de consideraçôes estratégicas dos EUA, que tinham interesse em fortalecer o aliado asiático na luta contra o Japão. O número de membros permanentes também foi sendo progressivamente aumentado: de três para quatro, e depois de quatro para cinco, com a inclusão da França gaullista, defendida incisivamente pela Grã-Bretanha. Onde traçar o limite da expansão era mais uma questão de conveniência política do que de aritmética ou de eficiência do órgão.

No Brasil, as opiniões se dividiram. Mesmo entre aqueles que viam a reivindicação com dificuldade, externou-se a opinião de que, caso algum país da América Latina fosse escolhido, esse lugar deveria caber ao Brasil. Getúlio Vargas, por seu turno, tinha a expectativa de que as aspirações do país seriam satisfeitas, como reconhecimento devido pela colaboração que o Brasil havia prestado aos Aliados. Com autorização presidencial, o governo brasileiro defendeu, como primeiro passo, um assento permanente para a América Latina. Uma vez criado o posto, seria definida sua forma de preenchimento por um país da região. Essa posição foi levada pelo Brasil à Conferência de Chapultepec e, posteriormente, a São Francisco. Confidencialmente, procurou-se alcançar o objetivo por meio de gestôes bilaterais junto aos EUA. O respaldo de Washington - particularmente 
de Roosevelt - era esperado como parte da "aliança preferencial" que haveria entre os dois países, pelo menos na visão do Rio de Janeiro. Mas, nos primeiros contatos mantidos, no final de 1944, o Departamento de Estado desestimulou as pretensões brasileiras.

No início de 1945, agravou-se o quadro de crise institucional que ameaçava a estabilidade do Estado Novo. Embora interessado no assento permanente, caso isso fosse factível, Vargas, mais preocupado com seu futuro político, não se engajou a fundo, deixando a tarefa à diplomacia brasileira. Quando Stettinius passou por Petrópolis para uma entrevista com Vargas, em fevereiro, o presidente nada pediu. Leão Velloso ainda tentaria insinuar o tema em conversas ocasionais com Stettinius, que tergiversou até São Francisco. No Comitê 1 da terceira Comissão, o Brasil chegou a apresentar proposta de emenda à Carta para conferir representação permanente à América Latina, sem êxito. Depois disso, a questão jamais se reabriu. Aquela janela de oportunidade se fechara.

Não obstante, seria exercício meramente especulativo imaginar se outra conjunção de fatores teria resultado em sucesso. O Brasil apostou na intercessão norte-americana como o caminho mais curto para alcançar seu objetivo. Essa estratégia falhou. A posição do governo dos EUA, aliás, evoluiu de 1944 para 1945, com marcante queda no interesse em reforçar o Brasil como seu principal aliado na América do Sul e no hemisfério ocidental. Essa linha havia sido seguida por Roosevelt em Dumbarton Oaks. Quando a Conferência de Yalta teve lugar, a conjuntura já havia em parte mudado. A guerra se aproximava do fim. O perigo maior havia passado. Ficara para trás a importância estratégica que o Brasil teve na luta contra o Eixo (bases aéreas no Nordeste) ou na contenção da Argentina "antiamericana". Quando Truman assume, não era mais imperativo cultivar a amizade de Vargas ou tolerar abusos de seu regime personalista. Com o processo de redemocratização em marcha acelerada no país, Washington progressivamente irá "abandonar" Vargas, finalmente deposto em outubro de 1945. Assim, quando mais o governo brasileiro ansiava pelo reconhecimento de sua lealdade, colhendo os frutos da relação especial que pensava manter, os EUA já não privilegiavam o Brasil como antes. Esse era só o início do desencantamento.

Recebido em 25 de outubro de 2010 Aprovado em 21 de dezembro de 2010

\section{Resumo}

Este artigo busca investigar como surgiu e se desenvolveu a hipótese de que o Brasil se tornasse um dos membros permanentes do Conselho de Segurança das Nações Unidas quando a organização foi criada em 1945. As motivações do presidente Roosevelt ao fazer essa proposta em 1944, durante a Conferência de Dumbarton Oaks, as resistências encontradas, assim como a posição que adotou o governo brasileiro na Conferência de São Francisco, são analisadas com base em fontes de arquivo e documentos do período em estudo. 
Palavras-chave: organizações internacionais; Nações Unidas; Conselho de Segurança; política externa brasileira; 1944-1945.

\section{Abstract}

This article aims at investigating how the hypothesis that Brazil could become one of the permanent members of the United Nations Security Council emerged and developed when the organization was created in 1945. The motivations of President Roosevelt in putting forward this proposal in 1944, during the Dumbarton Oaks Conference, the resistances faced, as well as the position adopted by the Brazilian government at the San Francisco Conference, are analyzed by using archival sources and documents from the period under examination.

Keywords: international organizations; United Nations; Security Council; Brazilian foreign policy; 1944-1945. 